\title{
Introduction to Design and Analysis of Torsional Vibration Dampers in Vehicle Industry
}

\author{
M. VENCZEL ${ }^{1}$, Á. VERESS ${ }^{2}$ \\ ${ }^{1}$ Budapest University of Technology and Economics, Faculty of Transportation Engineering and Vehicle \\ Engineering, Department of Aeronautics, Naval Architectures and Railway Vehicles, mvenczel@vrht.bme.hu \\ ${ }^{2}$ Budapest University of Technology and Economics, Faculty of Transportation Engineering and Vehicle \\ Engineering, Department of Aeronautics, Naval Architectures and Railway Vehicles; Knorr-Bremse Brake \\ Systems Ltd., R\&D Center Budapest, H-1119 Budapest, Major u. 69. Hungary. averess@vrht.bme.hu
}

\begin{abstract}
The crankshaft of today's internal combustion engines with high performance output are exposed to harmful torsional oscillations originated from the unbalanced gas and inertial forces. To avoid the fatigue damage of engine components, caused by the undesired vibrations, torsional vibration dampers can be applied. Viscodampers are one type of the torsional vibration dampers, which operational fluid is silicone oil. For cost-effective $R \& D$ activities and production, finite element and finite volume numerical discretization methods based calculation techniques must be involved into the engineering work supported by the modern computer technology. The aim of this paper is to provide an insight into the multidisciplinary design and development process of visco-dampers in vehicle industry applications. Four different examples as structural, fatigue, CFD analyses and structural optimization have been introduced in the present work. It turned out from the static structural and fatigue analyses, that the investigated damper has safety factor over the limit for both static structural and fatigue analyses, so it is suitable for the given load conditions. In the structural optimization process $34.36 \%$ mass reduction has been achieved. According to the coupled fluid dynamic and heat transfer simulations a rather stagnating air zone evolved between the engine and the damper during the operation, which can cause efficiency reduction of cooling fins mounted onto the housing. In light of the numerical results, the suitable damper position has been determined for the highest heat transfer.
\end{abstract}

Keywords: torsional vibration damper, stress and fatigue analysis, parametric optimization, CFD

\section{Introduction}

Fuel economy and emission are important aspects in the vehicle industry of nowadays. To meet the strict regulations and requirements for internal combustion engines, manufacturers are continuously developing new engine concepts and operating strategies such as downsizing (reducing the number of cylinders with higher rotational non-uniformity), downspeeding (operating the engine at smaller rotational speeds) and turbo-supercharging (operating the engine with higher torques). As a result, the intermittent combustion process in the pistons and the crankshaft's angle-dependent inertia lead to axial, transversal and torsional irregularities on the crankshaft. Torsional vibrations are considered to be the most dangerous, since their excitation frequency tends to match the natural frequency of the crankshaft and lead to noise, power loss, stability problem, fatigue damage and fracture of engine components. To avoid these malfunctions, torsional vibration dampers can be mounted onto the free- 
end of the crankshaft (see Figure 1) or integrated into the flywheel. Different types of torsional vibration dampers are available today such as frictional, rubber, viscous or spring. [1][2]

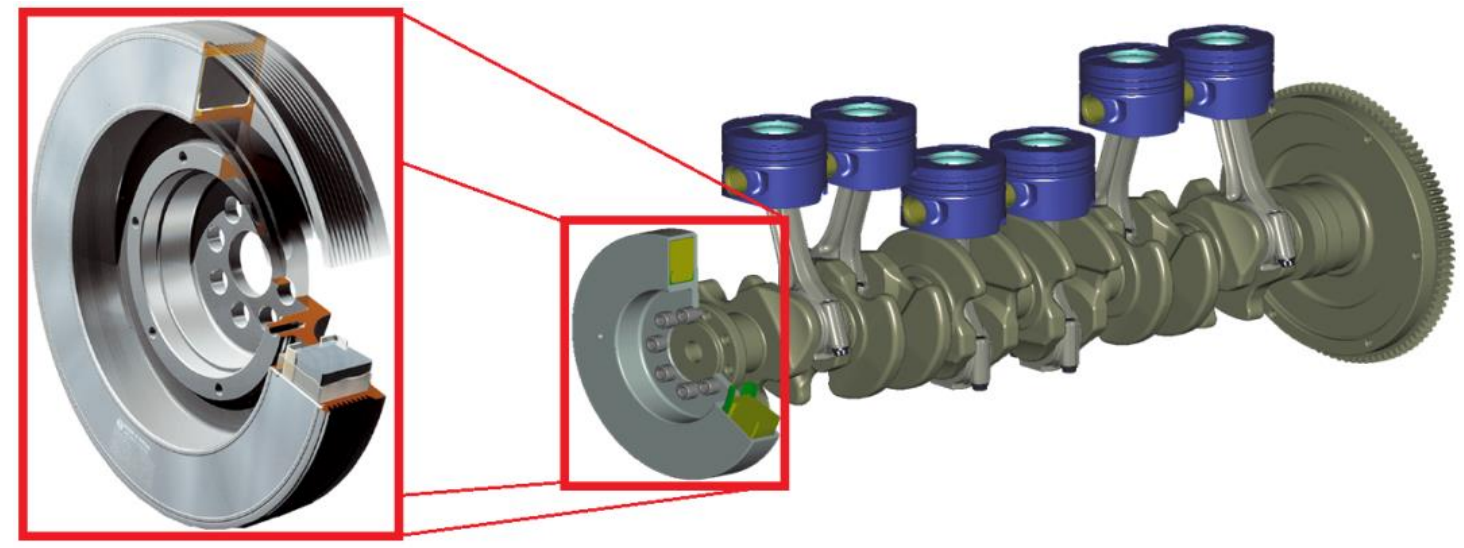

Figure 1. Visco-damper mounted onto the free-end of the crankshaft [3][4]

Viscous torsional vibration dampers (shortly visco-dampers) are one of the simplest devices in damping technology, which has working fluid of silicone oil. As presented in Figure 2, visco-dampers consist of a closed annular space (called housing) and a freely moving inertia ring. The inertia ring is guided by plastic slide bearings and the gap between housing and inertia ring is filled with silicone oil. Silicone oil is a non-Newtonian fluid and it has a different response to external impact compared to other conventional (Newtonian) fluids. The damping effect can be explained as follows: in case the crankshaft rotates undisturbedly without any oscillations, the inertia ring moves together with the housing without any slip. As long as just a minor torsional oscillation arises, the housing and the ring begin a relative movement while the oil suffers from circumferential shear stress (see right side of Figure 2). The damping effect is the sum of this shear stress calculated on the friction surfaces between the housing-cover and the ring. The relative difference in velocity, between the housing and the ring, influences the viscosity and thus the damping characteristics of the oil: higher velocity causes higher viscosity. According to the work of R. Andrä and J. H. Spurk [5], the damper's performance can be improved such a way, that the maximum energy dissipation will be obtained by realizing a damper whose damping constant times the shear viscosity divided by the product of effective shear modulus and moment of inertia ring equals one. Experiments also showed that in this tuning the dissipated energy, when polydimethylsiloxanes are used as damping fluids, can be as much as a factor of two higher than the maximum dissipated energy in case of Newtonian fluids. Because of these reasons, only visco-dampers filled with silicone oils can effectively eliminate the torsional vibrations at all frequencies. While the oscillations will be damped and converted into heat, the damping medium is exposed to high thermal load (originated from the friction and shearing of the oil layers), which is the primary lifetime influencing factor of visco-dampers. 

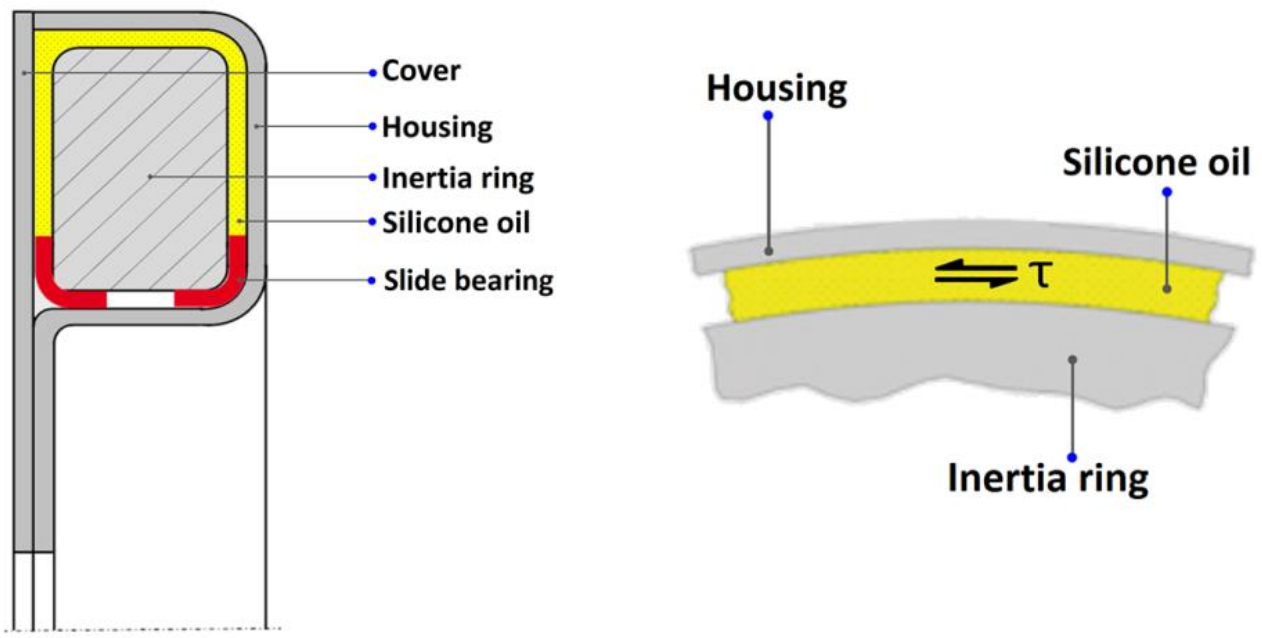

Figure 2. Structure of a visco-damper (left) and shear stress in the silicone oil (right) [4]

Since torsional vibration dampers are highly important vehicle structures from the operation and safety point of view, targeted and profound investigations must be carried out before production by means of stress, fatigue, fluid dynamic and thermal analyses. Nowadays, cost effective R\&D activities are the key factors for increasing market sharing and profit in the vehicle industry. Due to this demanding market situation and the complexity of the model, it is impossible to handle the problem in analytical way. Finite element and finite volume numerical discretization methods based calculation techniques must be involved into the engineering work supported by the modern computer technology. Structural optimization must be also performed to minimize development and production costs by means of mass and volume reduction, which, consequently, decreases material consumption. The importance of numerical optimization in engineering work is also proved by the work of Philipp Mall et al. [6], where a structural optimization of dual mass flywheel with internal damper was successfully completed based on the Augmented Lagrangian Particle Swarm Optimization (ALPSO) method. The damping problem was solved by finding a set of geometric parameters with minimal design space requirements and weight. The outcome of three different control parameter settings for the optimization algorithm were compared and it was found that the social-dominated parameter set was not applicable for the introduced problem as it showed very poor result quality, scattering, stability and very high computation costs. The balanced model showcased slightly better result quality and lower computation times, whereas the scattering was the lowest in case of the cognitivedominated model.

\section{Methods}

\subsection{Finite Element Method for Stress and Fatigue Analyses}

Basically, finite element calculation method based engineering software can be divided into three main modules as presented in Figure 3: preprocessor, solver and post-processor. 


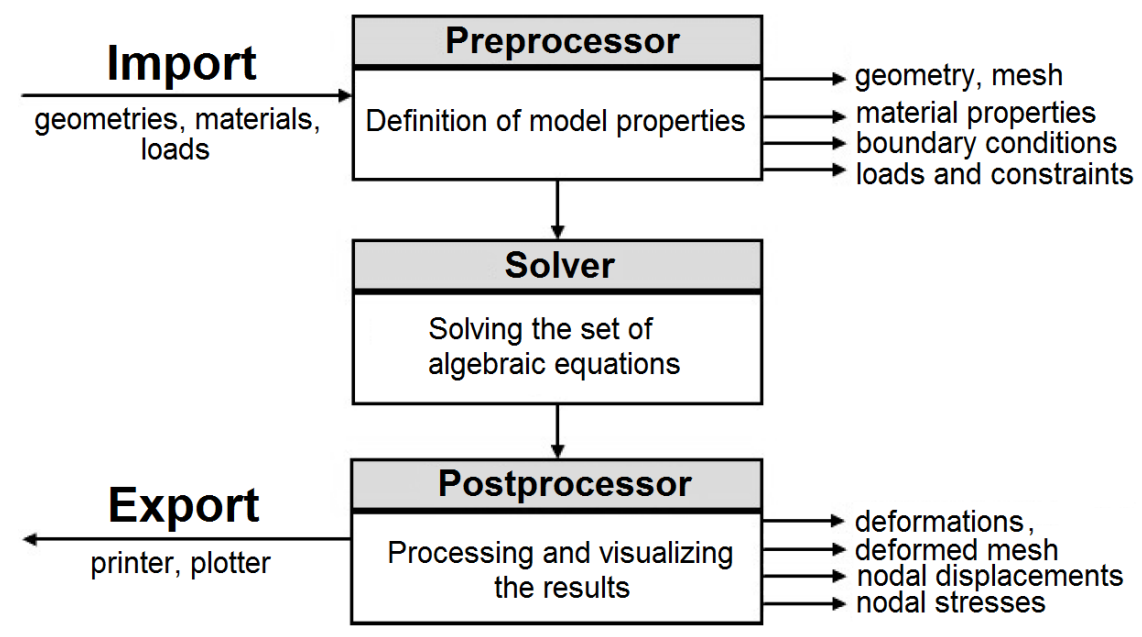

Figure 3. Structure of a finite element based engineering software [7]

Preprocessor is used to prepare the geometry, assign material properties (density, elastic modulus, yield strength, tensile strength, Poisson's ratio, etc.) to the model, perform the meshing, and to specify constraints and loads. The term "meshing" means the subdivision of investigated geometry into a finite number of non-intersecting parts (called finite elements). Approximate functions are applied within each finite element in order to describe the geometrical deformation well. The degree of these polynomial functions also determines the shape, curvature and flexibility of the finite elemental edge. The material laws allow the time-independent (linear elastic and isotropic or anisotropic materials, non-linear elastic materials, flexible-plastic materials) and time-dependent (materials prone to creep or relaxation) properties of the materials to be assigned to the numerical model. At this time, linear elastic and isotropic material law has been used for the calculation, where the behaviour of the metal components towards the elastic limit (yield strength) is governed by the Hooke's law (behaviour beyond the elastic limit is out of scope). The constraints determine the nodal degree of freedom, eliminate the statical overdetermination of the model and the singularity of the stiffness matrix $K$ (see in Eq. (1)). There are constraints for displacement and rotation. Both of them can be defined as free, bound (rigid or flexible) or guided. The most common types of loads in mechanical engineering problems are the following: nodal concentrated force, body force (inertia force), distributed load on the finite elemental surface or edge, residual stress or residual deformation (warping), thermal stress and bolt pretension. [7][8]

Solver is a mathematical relationship management program to solve any calculation problem. The parameters of the set of approximate functions will be obtained from the governing equilibrium equation of the finite element analysis (see Eq. (1)) with help of a suitable physical principle (i.e.: energy minimum): [7]

where

$$
\overline{\overline{\mathrm{K}}} \cdot \bar{U}=\bar{F}
$$

$\overline{\overline{\mathrm{K}}}$ - system stiffness matrix (contains material properties such as elastic and shear modulus)

$\bar{U}$ - vector of nodal displacements (result vector of the calculation)

$\bar{F}$ - generalized vector of loads 
The introduced governing equilibrium equation turns into a set of algebraic equations and the software solves this equation system for each node with continuous iteration steps until the final displacement tensors will be given for each element. After the deformations have been calculated from the acquired displacement values, the selected material law (Hooke's law in this case) can be applied to gain the nodal stress tensor values. As a result of the finite element analysis, the most important stress values for structural assessment, such as the axial stress-components the principal stresses (eigenvalues of the stress tensor) or the equivalent stresses (von Mises or Mohr), for each node of the investigated geometry will be given. [7]

Postprocessor is responsible for displaying the data set provided by the solver in an evaluable form. It includes mostly graphic displays and components wherewith the results can be clearly examined and demonstrated. The changes in the calculated values are visualized with contour lines and the bands between the lines are filled with different colours. [7]

Static structural stress analysis has been carried out on an assembly of simplified visco-damper geometry in ANSYS Static Structural submodule. The damper is attached to the crankshaft through bolt connections, thus the dummy shaft-end, washer and bolts have been also included in the model, while the inner parts of the damper (inertia ring, slide bearings and silicone oil) were not considered (as presented on left side of Figure 4). The effect of suppressed inner elements was taken into account in form of pressure and force loads. Weld seams between the cover and housing are one of the most important features of the assembly which have been considered as special bounded connections in the simulation. The remained contact surfaces have been defined with frictional contacts.
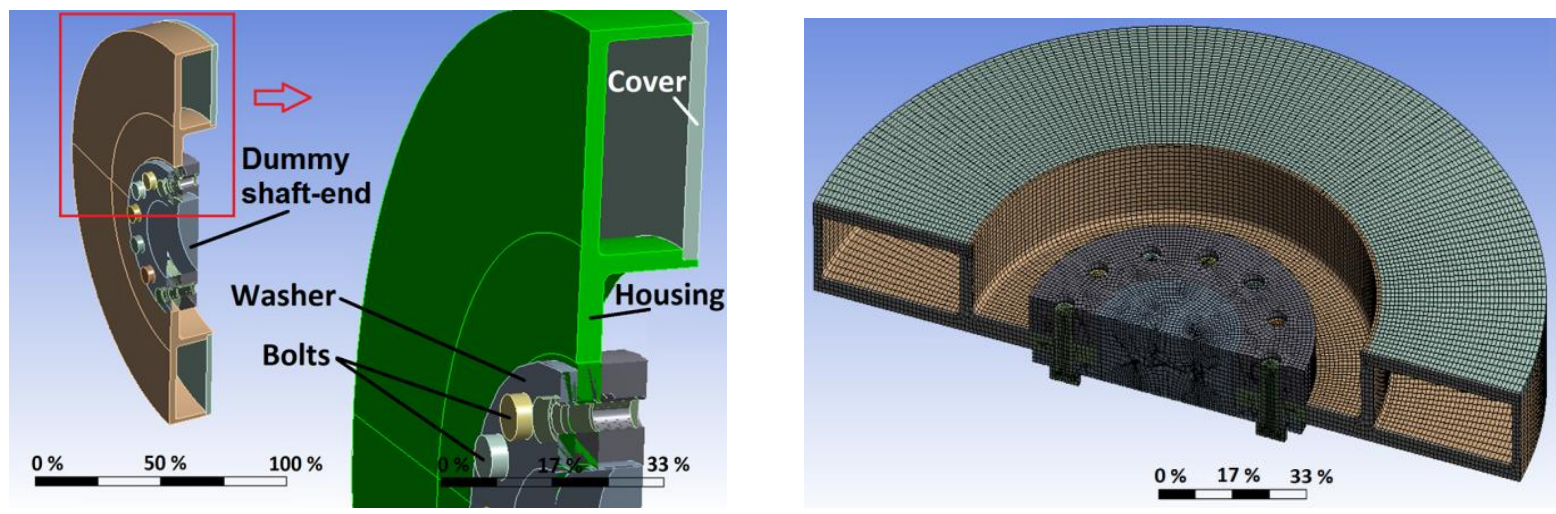

Figure 4. Investigated damper geometry and the generated numerical mesh for finite element analysis [8]

The applied numerical mesh (shown on right side of Figure 4) was generated by such ways that even the thinnest component (e.g.: cover) contains at least three element layers. The majority of the assembly is built up from hexahedron elements and the mesh in the region of weld seams is refined. The operation of visco-dampers involves a complex set of boundary conditions. The applied loads (and constraints) of the housing and cover in the simulation (see Figure 5) can be classified into two main groups: [8] 


\section{Static, quasi-static loads and constraint:}

Fixed support

Bolt pretension

Centrifugal force

Internal pressure

\section{Dynamic loads:}

Axial, radial and angular accelerations Inertia ring effect

Dynamic torque

Belt torque (only in one direction)

Belt force

Gravity force

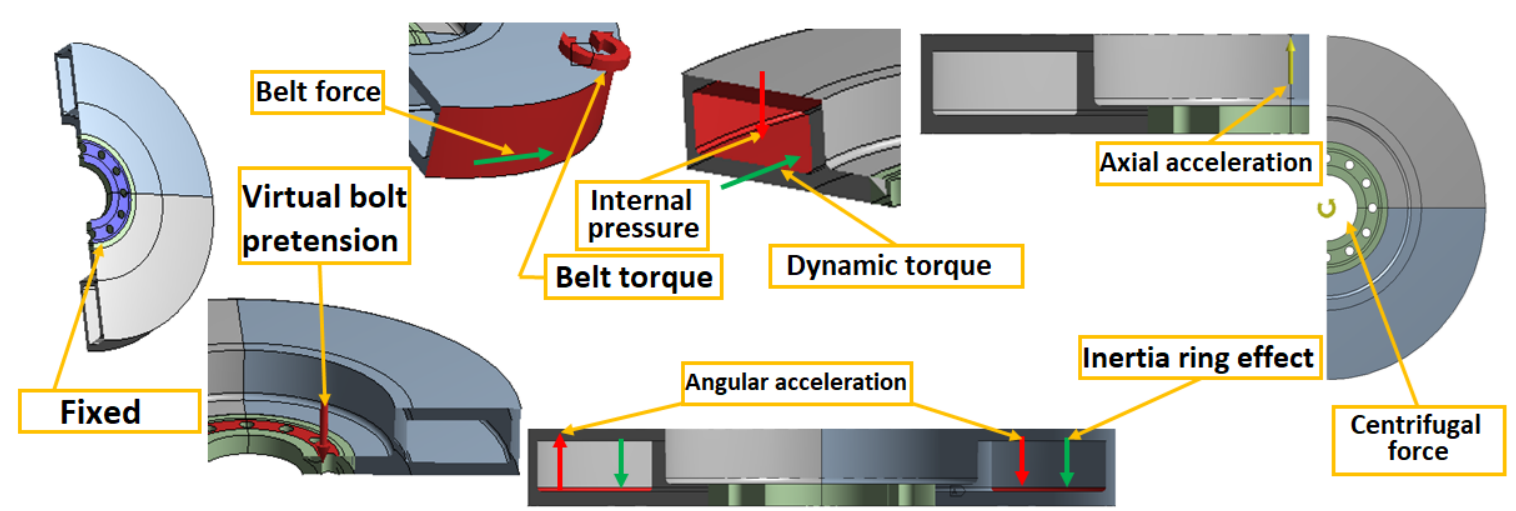

Figure 5. Defined loads and boundary conditions for finite element analysis [9]

The fixed support and bolt pretension boundary conditions are show in simplified manner in Figure 5, the fixed support is found on the end surface of the crank shaft-end and the bolt pretension forces are applied on a pre-specified cylindrical surface of the bolt as it is usual in the software.

Following the completeness of the simulation, the criterion for the correct operation is the yield limit including safety factor cannot be reached by the maximum equivalent stress at the nominated regions. Then, fatigue assessment has been induced with help of different type of load steps generated by dynamic loads (changes between positive and negative loads) in FEMFAT environment. Due to the fact, that real, three-dimensional components were investigated, the occurred stresses are also threedimensional and multiaxial, which must be assessed with uniaxial reference state. To realize this, the software employs an equivalent stress hypothesis, called Maximum Shear Strain Energy Criterion, to determine each nodal equivalent mean stresses and stress amplitudes together with cutting plane method for the most unfavourable situation par each node. As a result, safety factors related to fatigue limits have been visualized on the damper geometry in three-dimensional figures and the highest loaded point is shown in Haigh diagram. [8]

\subsection{Genetic Algorithm for Structural Optimization}

Recently three types of evolutionary algorithms for optimization purpose are available: genetic algorithm, evolutionary strategies and genetic programming. Genetic algorithm is a global stochastic based search method to determine the global optimum for complicated problems (high number of variable parameters) with several local optima. Genetic algorithm has been selected in this work since it is found to be robust, global and can be used at a small cost. The basic ideas and rules of the applied method are taken from the natural biological evolution and can be effectively used for parametric optimization problems when the examined system is not well known. [10] 
Genetic algorithms operate on the population consist of different potential individuals and employ principles (selection, recombination, mutation, reinsertion) to enhance its evolution. During the evolution loop, newer populations with better and better attributes will be generated (with better objective function values - adjust better to the environment), similarly to the natural adaptation. At the end of the evolution process, the most appropriate individual (solution of the optimization) will be selected from the final population (called Pareto). [9]

According to Figure 6, the global stochastic optimum searching procedure involves the following principles and steps): [10]

1. Generating initial population containing different individuals (randomization), specifying alterable parameters which influence the running time and memory consumption and predefining the cost functions. The fitness function will define a relative competence value for each individual.

2. Defining inheritance rules and generating new populations with genetic operations in a loop cycle:

Select parents means the transformation of relative competence value of an individual into an expected value of probability (this value takes part in making offspring) and then individuals will be selected for reproduction based on their relative competence value. Several selection methods are available such as roulette-wheel selection or stochastic universal sampling.

In recombination step, the selected individuals will be paired and crossover will happen.

Mutation means a minor change in the attribute of the recombined individual as it adds an increment to the original value of its variable. Mutation plays an important role in genetic algorithm, as it avoids the recurrence in population during evolution and it is used to ensure that the good genetic information is not lost during selection and recombination.

The last step for gaining the new population is the reinsertion. The selection of individuals for replacement can be done in a random manner (uniform selection) or based on the relative competence value of the individuals (competence based selection).

3. The most appropriate individual will be selected after the last iteration step from the final population with help of the predefined cost functions. 


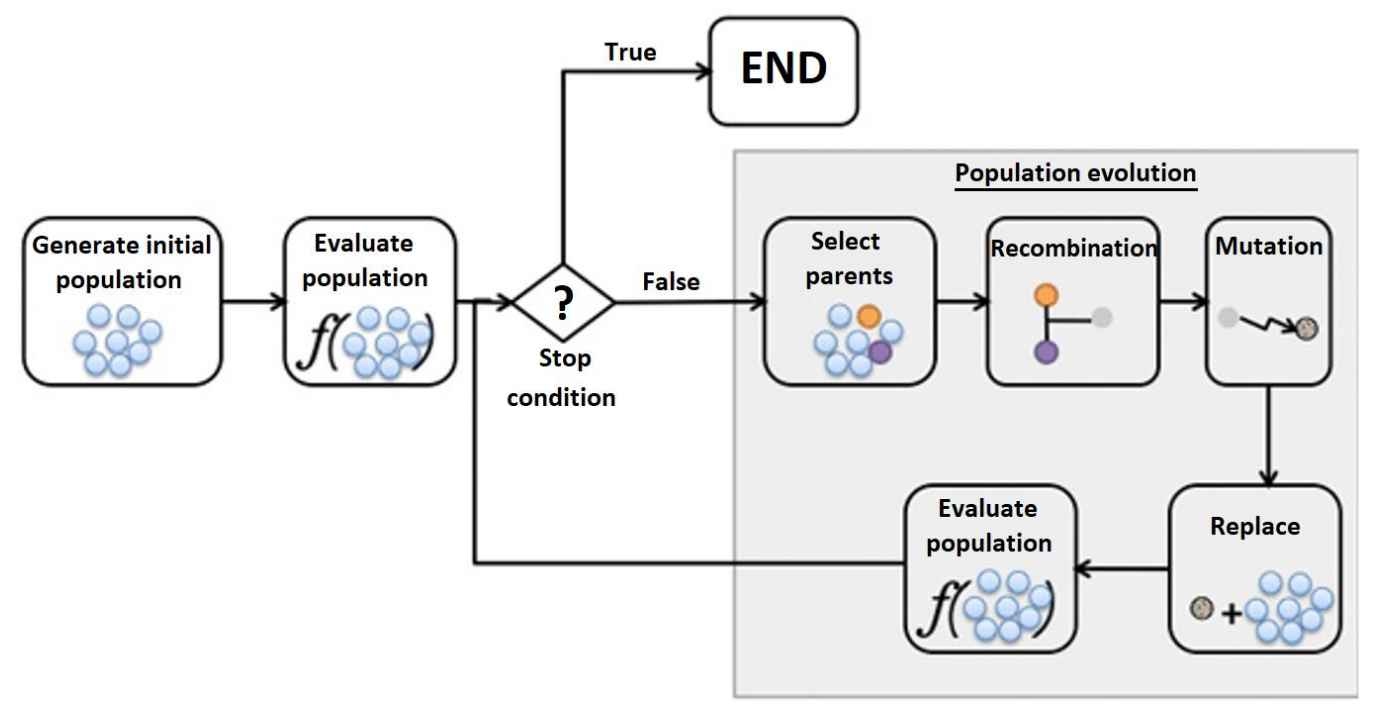

Figure 6. Scheme of the genetic algorithm [9]

Genetic algorithm has been used for structural optimization on a simplified, three-dimensional viscodamper geometry (without dummy shaft-end, washer, bolts and weld seams as shown on the left side of Figure 7), compared to the one presented in subchapter 2.1, with special care for minimizing the mass at given allowable equivalent stress limit over reasonable computational cost. The task was performed in ANSYS DesignXplorer submodule, where the same loads, constraints and boundary conditions have been defined as presented in Figure 5.
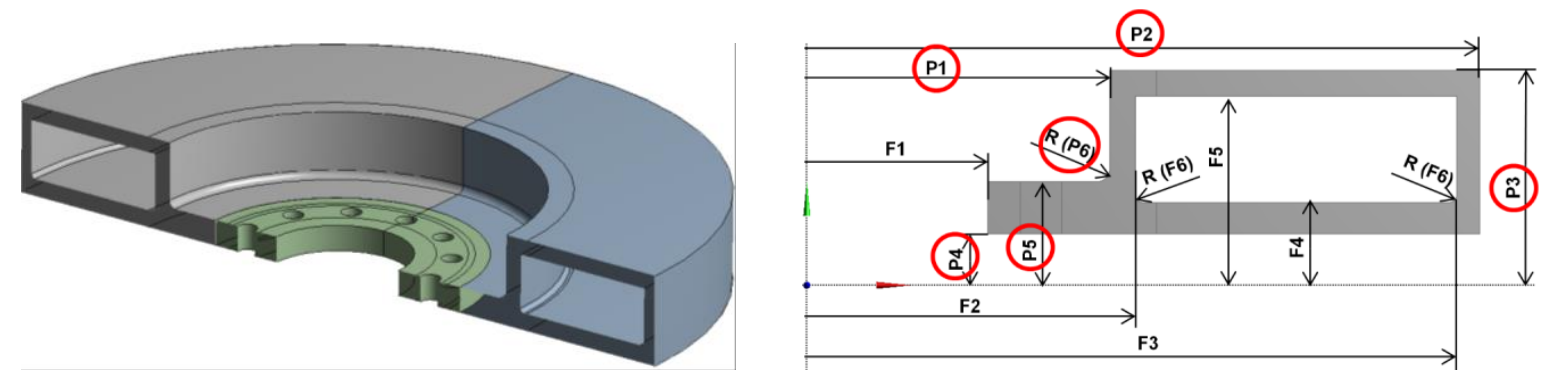

Figure 7. Initial geometry for optimization (left) and modifiable parameters (right) [9]

The adjustable geometrical parameters have been defined by previous analysis for optimization and are marked with red circles on the right side of Figure 7. At the end of the structural optimization process, the predefined cost function will determine the most appropriate individual from the final population.

\subsection{Finite Volume Method for Coupled Fluid Dynamic and Heat Transfer Analysis}

Special care must be taken into consideration also at the inside part of the visco-damper, where the undesired vibrations will be damped and converted into certain amount of heat. The dissipated heat causes increasing temperature and influences the viscosity, damping characteristics and lifetime of the damping fluid. The finite volume method based ANSYS CFX submodule has been used for modelling fluid dynamic and heat transfer processes to determine temperature distribution in the visco-damper. 
The structure of finite volume type simulation process based engineering software is similar to the finite element one (discussed in subchapter 2.1.) as it contains a preprocessor, a solver and a postprocessor module as well. In the pre-processing step, the domains of the target geometry will be created as fluid domain(s). The investigated domains are then discretized into a set of control volumes (called cells) as shown in Figure 8. The fundamental governing equations of fluid dynamics (the general conservation or transport equations for mass, momentum, energy, etc.) form a system of nonlinear partial differential equations that do not have closed form solution yet over any kind and size of general and complex flows. The governing equations are written in a compact and versatile form in Eq. (2): [11]

where

$$
\frac{\partial}{\partial t} \int_{V} \rho \Phi d V+\oint_{A} \rho \Phi \boldsymbol{V} d \boldsymbol{A}=\oint_{A} \Gamma_{\Phi} \nabla \Phi d \boldsymbol{A}+\int_{V} S_{\Phi} d V
$$

$$
\begin{aligned}
& t \text { - time } \\
& V \text { - domain volume } \\
& \rho \text { - density } \\
& A-\text { domain surface } \\
& \Gamma \text { - circulation } \\
& \nabla-\text { nabla operator } \\
& S \text { - source term }
\end{aligned}
$$

$\Phi$ - equation type parameter: $\quad \Phi=1 \rightarrow$ continuity equation

$\Phi=u \rightarrow$ momentum equation in $\mathrm{X}$ direction

$\Phi=v \rightarrow$ momentum equation in $\mathrm{Y}$ direction

$\Phi=w \rightarrow$ momentum equation in $\mathrm{Z}$ direction

$\Phi=h \rightarrow$ energy equation

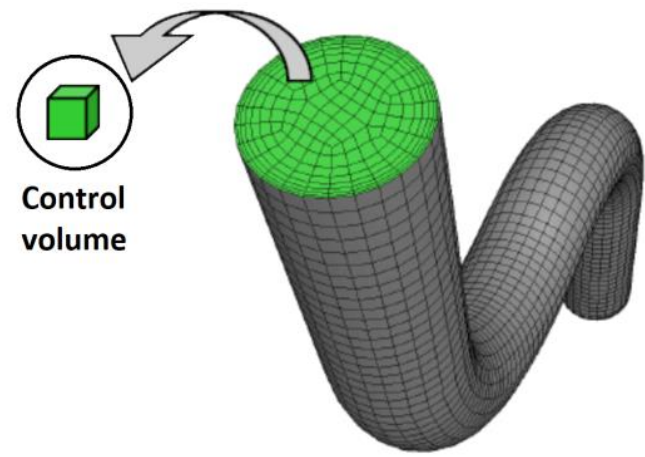

Figure 8. Discretized CFD domain with control volumes [11]

Turbulence is a chaotic phenomenon in the flow field, when the flow characteristics fluctuate in time and space and it can have a significant effect on the results. Taking into consideration the turbulence with statistical averaging and with different turbulence models, the nonlinear partial differential equations can be closed, following the Boussinesq approximation, and numerically solved. The governing equations are discretized into a system of linearized algebraic equations and will be solved numerically on the set of control volumes as the solver intends to replace the variables with numbers, and advances these numbers in space and time through iteration steps in order to render the solution field. [12] 
The recently used CFD tool (ANSYS CFX) can be applied for analysing fluid flow problems only in case the flow characteristics meet the continuum mechanic requirements, thus Knudsen-number must be smaller than 0.01 in these analyses. The Knudsen-number can be estimated by Eq. (3). [13]

where

$$
K n=\frac{\lambda}{L}=\frac{\frac{R \cdot T}{\sqrt{2} \cdot \pi \cdot d_{a}^{2} \cdot A \cdot p}}{L}<0.01
$$

$K n$ - Knudsen-number

$\lambda-$ mean free path of molecules

$R-$ specific gas constant

$T$ - temperature

$d_{a}$ - averaged molecule diameter

$A-$ Avogadro's number

$p$ - pressure

$L$ - length scale (smallest size of mesh elements)

A three-dimensional damper segment (see left side of Figure 9) has been numerically investigated where the impact of cooling fins and the effect of engine-side and the proximity of engine have been also considered. The boundaries of the ambient domain have been set far enough from the investigated damper-shaft-engine system so that the disturbances, originated from the boundaries, will not affect the numerical results of the assembly.
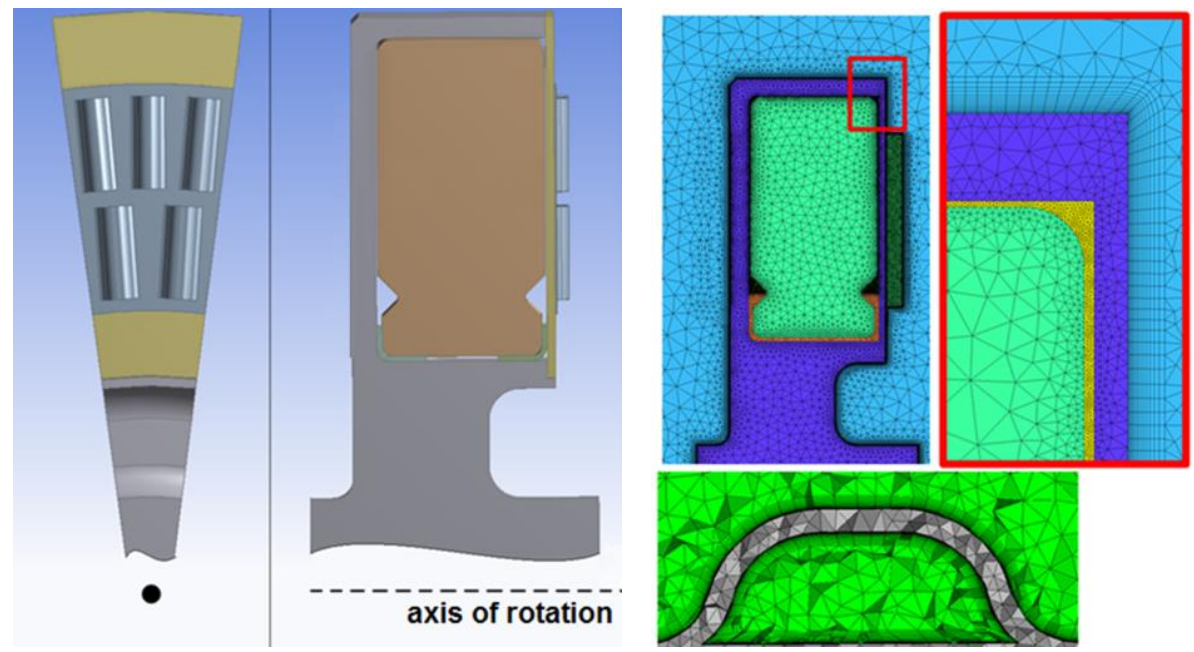

Figure 9. Geometry (left) and generated numerical mesh with boundary layers (right) for CFD analysis

The numerical mesh must be able to capture the complexity of the model and all relevant fluid dynamic and heat transfer phenomena, related to the operation of a visco-damper, with acceptable accuracy. Near the solid walls (damper housing and cover, cooling fins, shaft and engine) the effect of boundary layers must be also taken into account with using finer mesh (as presented on right side of Figure 9) to capture the flow and the heat transfer process correctly. This requires a short preliminary 
calculation for determining the first cell height from the wall with using Eq. (4) [14] and for the boundary thickness with Eq. (5) [15].

$$
y=\frac{y^{+} \cdot v}{U_{\tau}}
$$

where

$y$ - first cell height from the wall

$y^{+}$- dimensionless wall distance

$v$ - kinematic viscosity

$U_{\tau}-$ wall shear velocity

$$
\delta=0.035 \cdot L \cdot R e^{-\frac{1}{7}}
$$

where

$$
\begin{aligned}
& \delta \text { - boundary thickness } \\
& L \text { - specific length } \\
& R e \text { - Reynolds number }
\end{aligned}
$$

Based on Figure 10, opening condition has been applied on the boundary surfaces of the ambient domain while the heating effect of the engine was taken into consideration with constant temperature walls. Volume heat source has been defined on the silicone oil domain (considering heat generation due to friction and shearing of oil layers). Interfaces have been defined between different domains for the heat transfer processes. The rotational periodicity boundary condition modifies the CFD results as the investigated geometry would be a complete model instead of a segment.

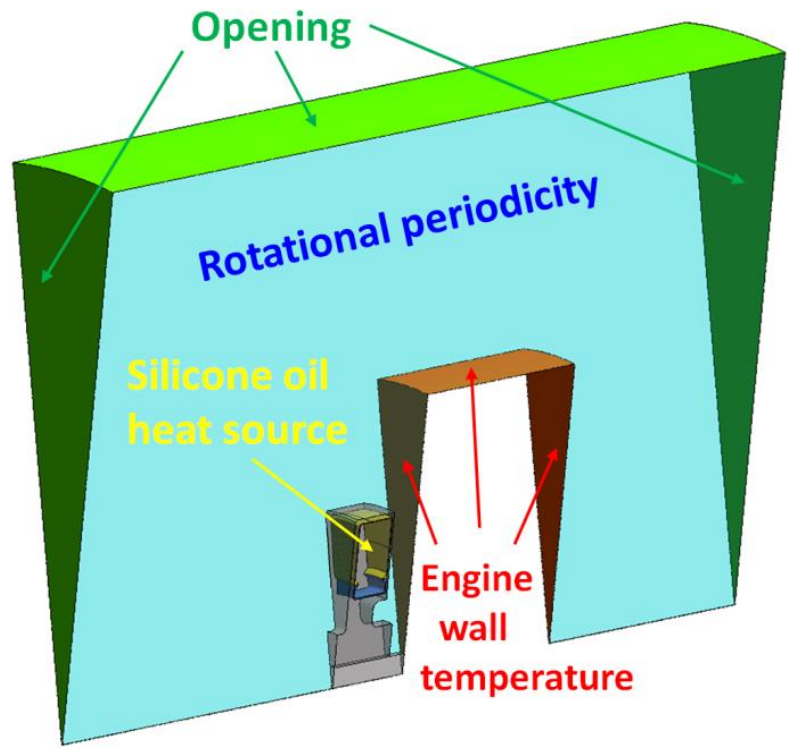

Figure 10. Defined boundary conditions for CFD analysis

ANSYS CFX uses a co-located (non-staggered) grid layout to avoid the decoupling of pressure and velocity values during calculation and to remove the dependence of the steady-state solution on the time step. The discrete system of linearized equations will be solved with a so-called Multigrid Accelerated Incomplete Lower Upper Factorization technique, which is an iterative method, where the 
exact solution of the equations is approached through iteration steps. The mentioned linearized system of discrete equations can be written in matrix form by Eq. (6). [16]

$$
\overline{\overline{\mathrm{A}}} \cdot \bar{\varphi}=\bar{b}
$$

where

$\overline{\overline{\mathrm{A}}}$ - coefficient matrix

$\bar{\varphi}-$ solution vector

$\bar{b}$ - right hand side of the equations (vector)

\section{Results}

\subsection{Stress and Fatigue Analyses - Results}

Converged numerical results have been obtained and evaluated both for the housing and for the cover components in terms of equivalent stress and principal stress first. The maximum von Mises equivalent stress is below the Rp/1.5 according to FKM standard. Safety factors, related to fatigue assessment, have been determined and visualized also both on three-dimensional figures of the damper geometry (see Figure 11) and in Haigh-diagrams in order to find the point with the lowest value in the investigated damper geometry. It turned out from the results that the maximally loaded point is found at the inner corner of the housing geometry. The normalized value of the safety factor $(13.98 \%)$ in this point is well above the acceptable limit (4.33\%), thus the investigated geometry is suitable for the given fatigue load conditions.

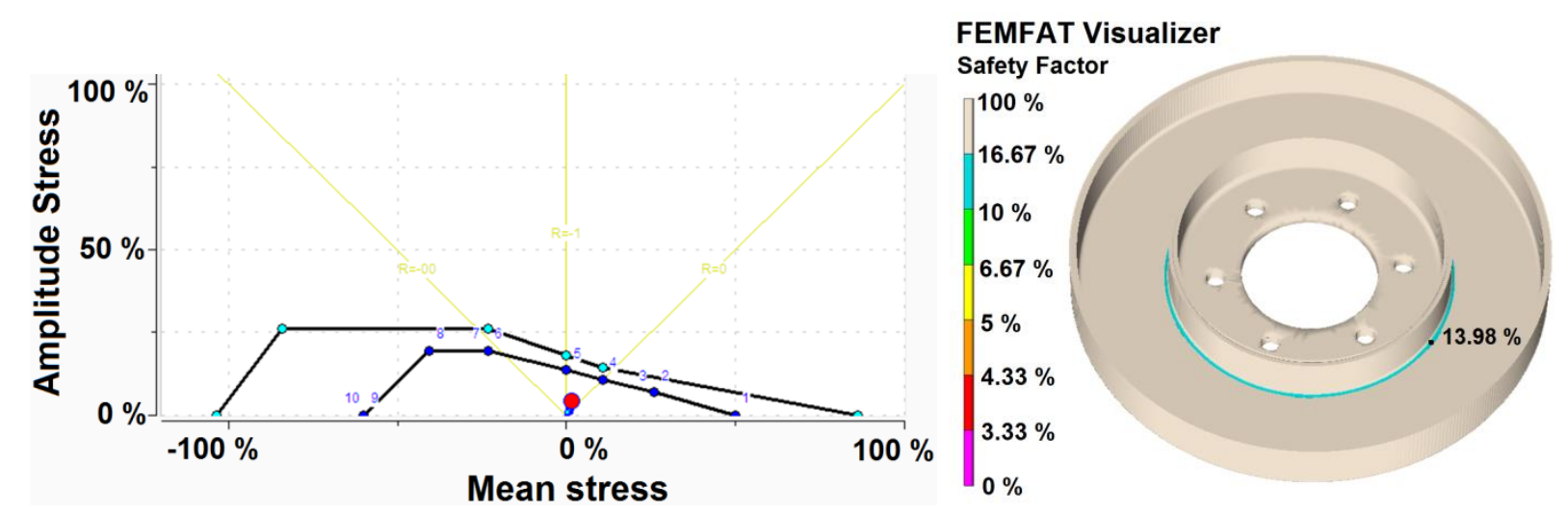

Figure 11. Haigh diagram (left) and safety factors (right) of the housing by fatigue analysis

\subsection{Structural Optimization - Results}

Left side of Figure 12 shows the final population of the structural optimization process. The horizontal line represents the limit of feasibility as individuals above this line (grey dots) are not viable due to high equivalent stress values. The most appropriate individual (marked with green circle) has been selected based on the optimization criteria: minimal mass with maximal allowable static stress considered safety factor. At the end of the structural optimization process, the achieved rate of mass 
reduction was 34.36\%. Another static structural analysis has been performed with the acquired optimized parameters on an extended damper geometry (modelling dummy crankshaft-end, washer, bolts and weld seams as well) to check the correctness of the applied simplifications for optimization. According to the right side of Figure 12, the analysis showed higher (but allowable) equivalent stress values due to improved utilization of the damper geometry.
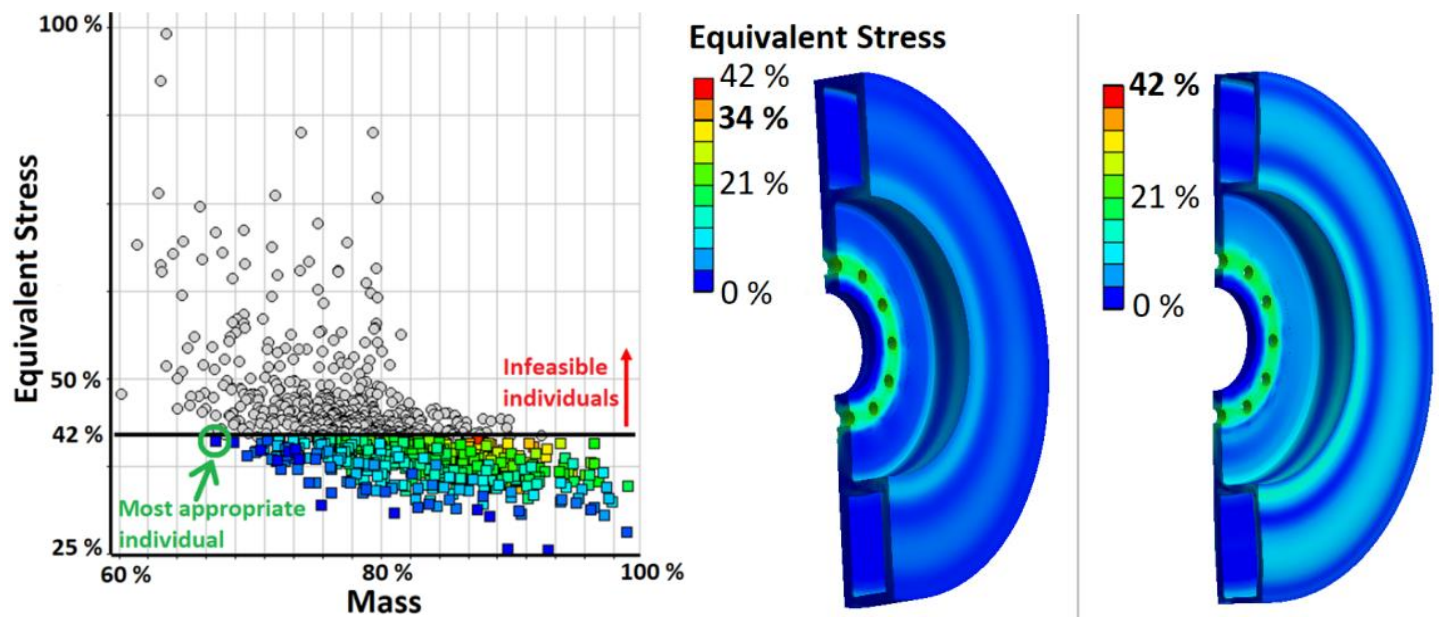

Figure 12. Final population of the optimization (left) and comparison of initial and optimized models (right) [9]

\subsection{Coupled Fluid Dynamic and Heat Transfer Results}

The previously set-up and executed CFD simulation provided converged numerical results. Streamlines around the assembly, heat flux on the outer surface of the damper and the temperature distribution along the geometry have been thoroughly analysed. According to the streamline result (see left side of Figure 13), a turbulent region of air evolved between the engine and the damper (called engine-damper-gap) during the operation. Air is stuck in this region due to the lack of free stream. Because of this, the mounted cooling fins, working in the engine-damper-gap, provide lower cooling efficiency. It can be proved by the heat transfer result (see centre of Figure 13,) as well. The intensity of heat transfer on the engine-damper-gap side is found to be significantly lower compared to the free-side surrounded by free stream. Consequently, it is beneficial to mount the cooling fins onto the free-side of the damper, far away from the engine in order to increase the heat transfer (see right side of Figure 13).
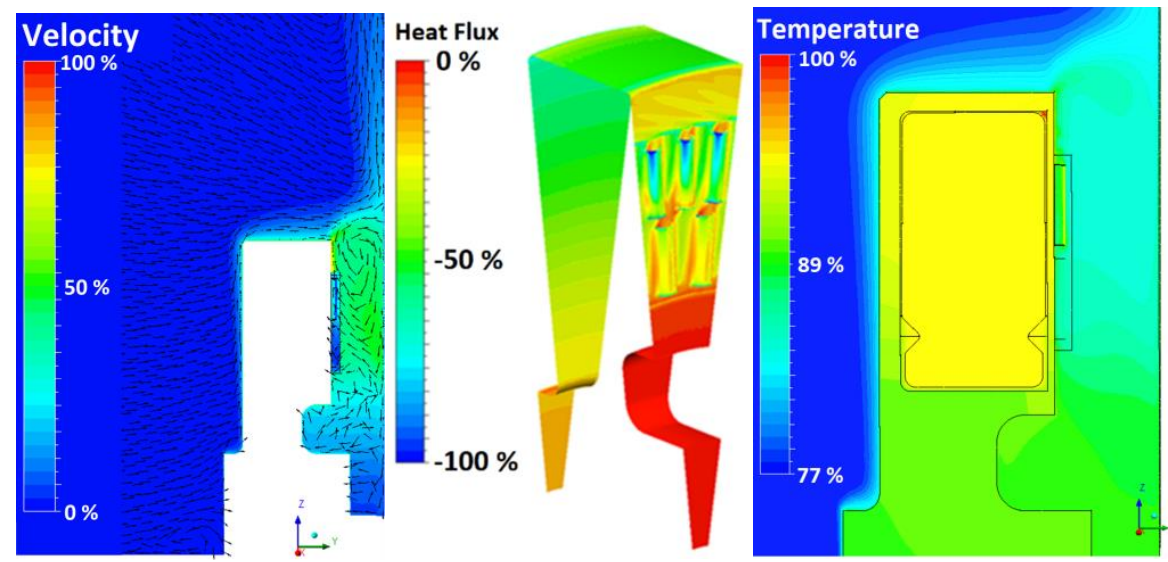

Figure 13. Streamlines (left), heat flux (centre) and temperature (right) fields of the CFD analysis 


\section{Conclusions}

Torsional vibration dampers are considered to be one of the most important vehicle structures from the operation and safety point of view. Visco-dampers filled with silicone oil and can effectively eliminate the torsional vibrations on the crankshaft and contribute to the expected lifetime of the engine. Design and development of this type of products involve strict requirements, compound loads and several influencing factors. Considering the demanding market situation and the complexity of the model it is impossible to handle the problem in analytical way. Finite element and finite volume numerical discretization methods based calculation techniques must be involved into the engineering work supported by the modern computer technology. Finite element method based stress and fatigue analyses, genetic algorithm based structural optimization and finite volume based coupled fluid dynamic and heat transfer simulation have been performed on real visco-damper geometries.

The static stress and fatigue calculations highlighted, that the most loaded points of the investigated assembly is located at the inner corner of the housing geometry. The safety factor in this point is well above the acceptable limit, thus the investigated geometry is suitable for the given fatigue load conditions. Although the presented stress and fatigue calculations have been completed on a damper geometry where the weld seam links (between housing and cover) were modelled by bounded connections, further analyses are desired to check the effect of different types of weld seam models on the stress and fatigue results. A damper mass reduction rate of $34.36 \%$ has been achieved by parametric optimization based on genetic algorithm and sensitivity analysis. The optimized damper geometry showed slightly higher (but allowable) static stress values due to the improved geometrical utilization. The outcome of the coupled fluid dynamic and heat transfer simulation reveals the consequences of correctly mounted cooling fins. Cooling efficiency of the damper can be effectively improved by positioning the fins into free stream, opposite to the engine side. As a next step, the effect of high temperatures, gap sizes and cooling fin geometries on the life time of damping fluid should be thoroughly investigated and built into the product development process in form of a reliable lifetime calculation method.

\section{Acknowledgements}

The publication of the work reported herein has been supported by ETDB at BME and the Hungarian Automotive Higher Education Foundation (MAF).

\section{References}

[1] W. Homik (2010) Diagnostics, maintenance and regeneration of torsional vibration dampers for crankshafts of ship diesel engines. Polish Maritime Research. Vol 17, 62-68. url: http://yadda.icm.edu.pl/yadda/element/bwmeta1.element.baztech-article-BWM4-00280077/c/diagnostics01_2010_09.pdf (12.11.2018)

[2] J. Pfleghaar - B. Lohmann (2013) The Electrical Dual Mass Flywheel - an Efficient Active Damping System, The International Federation of Automatic Control. 46, Issue 21, 483-488, url: https://www.sciencedirect.com/science/article/pii/S1474667016384178(12.11.2018) 
[3] P. Érsek (2008) Numerische Untersuchung der Auffüllung eines Torsiondämpfers mit Silikonöl, Knorr-Bremse R\&D Center Budapest, Technische und Wirtshaftwissenschaftliche Universität Budapest, Lehrstuhl für Hydrodynamische Systeme, Diplomarbeit, Budapest, Ungarn.

[4] http://www.hassewrede.de/media/documents/Serviceflyer.pdf (12.11.2018)

[5] R. Andrä - J. H. Spurk (1982) Torsional Damper for Maximum Energy Absorption with Equilibrated Polydimethylsiloxanes as Damping Fluids, Journal of Sound and Vibration, 1982, Vol 82, Issue 4, 465-472, url: https://www.sciencedirect.com/science/article/pii/0022460X82904011 (12.11.2018)

[6] P. Mall - A. Fidlin - A. Krüger - H. Groß (2017)Simulation based optimization of torsional vibration dampers in automotive powertrains, Mechanism and Machine Theory, Vol 115, 244266, url: https://www.sciencedirect.com/science/article/pii/S0094114X16304049?via\%3Dihub (12.11.2018)

[7] J. Devecz - A. Eleőd - J. Márialigeti - G. László (2012) Jármütervezés és vizsgálat alapjai, Typotex Kiadó,

https://www.tankonyvtar.hu/hu/tartalom/tamop412A/0018_Jarmutervezes_es_vizsgalat/adatok.html (12.11.2018)

[8] M. Erdősi - Á. Veress Á. (2013) Torziós lengéscsillapító szilárdsági és élettartam vizsgálata véges elem módszerrel, diplomamunka, Budapesti Műszaki és Gazdaságtudományi Egyetem, Vasúti Járművek, Repülőgépek és Hajók Tanszék.

[9] G. Rácz - Á. Veress - L. Palkovics L. (2014) Torziós lengéscsillapítók szilárdságtani optimalizációja, A Jövő Járműve, Vol 5, Issue 1-2, 19-24, url: http://www.sze.hu/ jret/AJJ/AJJ_201412.pdf (12.11.2018)

[10] B. Lantos (2015) Fuzzy Systems and Genetic Algorithms, ResearchGate. url: https://www.researchgate.net/publication/268174555_FUZZY_SYSTEMS_AND_GENETIC_ALGO RITHMS (12.11.2018)

[11] https://www.esss.co/blog/es/dinamica-de-fluidos-computacional-que-es/ (12.11.2018)

[12] https://en.wikipedia.org/wiki/Turbulence_modeling (12.11.2018)

[13] https://en.wikipedia.org/wiki/Knudsen_number (12.11.2018)

[14] https://www.computationalfluiddynamics.com.au/tips-tricks-cfd-estimate-first-cell-height/ (12.11.2018)

[15] J. V. Nunes de Sousa - A. R. Lins de Macêdo - W. F. A. Junior - A. G. Barbosa de Lima (2014) Numerical Analysis of Turbulent Fluid Flow and Drag Coefficient for Optimizing the AUV Hull Design, Open Journal of Fluid Dynamics, Vol 4, 263-277, url: https://file.scirp.org/pdf/OJFD_2014090514423520.pdf (12.11.2018)

[16] https://www.sharcnet.ca/Software/Ansys/16.2.3/en-us/help/cfx_thry/i1312256.html (12.11.2018) 